\title{
Design and Fabrication of Chainless Bicycle with Folding Mechanism
}

\author{
Rajkumar Bagade $^{1}$, Prerak Kharabe ${ }^{2}$, Harshad Sathawane ${ }^{3}$, Sandesh Borker ${ }^{4}$ \\ Prof.Sharayu Wasu ${ }^{5}$, Prof. Swapnil Choudhary ${ }^{6}$,Prof. Dr. Bharat Chede ${ }^{7}$ \\ ${ }^{1234}$ U.G.Student, Wainganga College of Engineering And Management, Maharashtra, India \\ ${ }^{5,6,7}$ Assistant Professor, Wainganga College of Engineering And Management, Maharashtra, India
}

\begin{abstract}
A folding bicycle with crank mechanism is a bicycle designed to fold into a compact form, facilitating transport and storage. When folded, the bikes can be more easily carried into buildings, on public transportation (facilitating mixed-mode commuting and bicycle commuting), and more easily stored in compact living quarters or aboard a car, boat or plane. Folding mechanisms vary, with each offering a distinct combination of folding speed, folding ease, compactness, ride, weight, durability, and price. Distinguished by the complexities of their folding mechanism, more demanding structural requirements, greater number of parts, and more specialized market appeal, folding bikes may be more expensive than comparable non-folding models. The choice of model, apart from cost considerations, is a matter of resolving the various practical requirements: a quick easy fold, a compact folded size, or a faster but less compact model.
\end{abstract}

Keywords- Chainless, Bicycle, Mechanism, Pedal, Design

\section{I - INTRODUCTION}

A bicycle, often called a bike or cycle, is a humanpowered, pedal-driven, single-track vehicle, having two wheels attached to a frame, one behind the other. A bicycle rider is called a cyclist, or bicyclist. Bicycles were introduced in the 19th century in Europe and as of
2003, more than 1 billion have been produced worldwide, twice as many as the number of automobiles that have been produced. They are the principal means of transportation in many regions. They also provide a popular form of recreation, and have been adapted for use as children's toys, general fitness, military and police applications, courier services, and bicycle racing. The basic shape and configuration of a

typical upright, or safety bicycle, has changed little since the first chain-driven model was developed around 1885 . But many details have been improved, especially since the advent of modern materials and computer-aided design. These have allowed for a proliferation of specialized designs for many types of cycling.

The bicycle's invention has had an enormous effect on society, both in terms of culture and of advancing modern industrial methods. Several components that eventually played a key role in the development of the automobile were initially invented for use in the bicycle, including ball bearings, pneumatic tires, chain-driven sprockets, and tension-spooked wheels Pedaling the Pedal Exerciser is Noisy. Some machines are noisy because they squeak or their tension mechanism is adjusted by friction control knob. This can end up getting quite loud. One way to dampen this is to try 


\section{International Journal of Innovations in Engineering and Science, www.ijies.net}

some graphite powder on the surface where the knob clamps down. Other reasons that your machine could create noise is because you have it on a hard surface and the movement of the pedals is being echoed or the vibration (even a little bit) is picked up and carried over the floors surface. Try putting down a piece of carpet or a noise. Another alternative is to choose a pedaled with a magnetic resistance system instead of friction. Not only are these machines quieter, they are superior design

\section{II - LETERATURE REVIEW}

The first shaft drives for cycles appear to have been invented independently in 1890 in the United States and England. The Drive shafts are carriers of torque; they are subject to torsion and shear stress, which represents the difference between the input force and the load. They thus need to be strong enough to bear the stress, without imposing too great an additional inertia by virtue of the weight of the shaft. Most automobiles today use rigid driveshaft to deliver power from a transmission to the wheels. A pair of short driveshaft is commonly used to send power from a central differential, transmission, or transaxie to the wheels.

\subsection{Planetary Gear Train}

A planetary gear train is a gear train contains at least one gear (planet) which is required to rotate above its own axis and another axis. A simple sun gear is a sun gear if it is adjacent to one planet only, and a simple carrier is a carrier if it is adjacent to one planet only or several serial planets.If all sun gears and all carriers are simple sun gears and simple carriers, the planetary gear train is called non-coupled planetary gear train; otherwise, it is called coupled planetary gear train. Figures 2(a) and 2(b) show the non- coupled planetary gear train and coupled planetary gear train, respectively.

\subsection{Automatic speed changer}

The automatic speed changer can be divided into step speed changer and continuously variable speed changer. In turn the step speed changer can be divided into the fixed-axle gear type and the planetary gear type according to the gear train mechanism used in it. The automatic step speed changer uses the centrifugal clutch inducting the engine (motor) speed to change the gear position. The automatic speed changer is composed of several clutches, brakes and shifting control device and its whole operating process uses the clutch (or brake) to automatically change the reduction ratio. Thus provide the bicycle (motorcycle) with better maneuvering.

\subsection{Half- or mid-fold}

Many folding frames follow the classic frame pattern of the safety bicycle's diamond frame, but feature a hinge point (with single or double hinges) allowing the bicycle to fold approximately in half. Quick-release clamps enable raising or lowering steering and seat columns. A similar swing hinge may be combined with a folding steering column. Fold designs may use larger wheels, even the same size as in non-folders, for users prioritizing ride over fold compactness. Bikes that use this kind of fold include Dahon, and Montague, and Tern

\subsection{Vertical Fold}

Instead of folding horizontally, this style of bike has one or two hinges along the main tube and/or chain and seat stays that allow the bike to fold vertically. The result leaves the two wheels side by side but is often more compact than a horizontally hinged design. The Brampton and Dahon Speed Uno both feature

\section{III - DESIGN AND METHODOLOGY}

In our attempt to design a special purpose machine we have adopted a very a very careful approach, the total design work has been divided into two parts mainly

- System design

- Mechanical design

System design mainly concerns with the various physical constraints and ergonomics ,space requirements, arrangement of various components on the main frame of machine no of controls position of these controls ease of maintenance scope of further improvement ; weight of $\mathrm{m} / \mathrm{c}$ from ground.

In Mechanical design the component in two categories.

- Design parts

- Parts to be purchased.

For design parts detail design is done and dimensions thus obtained are compared to next highest dimension which are readily available in market this simplifies the assembly as well as post production servicing work.

The various tolerance on work are specified in the manufacturing drawings the process charts are prepared $\&$ passed on to the manufacturing stage .The parts are to be purchased directly are specified \&selected from standard catalogues. 


\section{International Journal of Innovations in Engineering and Science, www.ijies.net}

Fig. 2 - Drive Link

\section{IV - CONTRUCTION AND WORING}

1) Base Frame - The bi-cycle frame is made of ms pipe which consists of the front steering arm, rear wheel bracket, seat system.

2) Wheel system - The front wheel is mounted on the front fork, whereas the rear wheels are mounted on rear wheel shaft, which is held in ball bearings in housings on the base frame

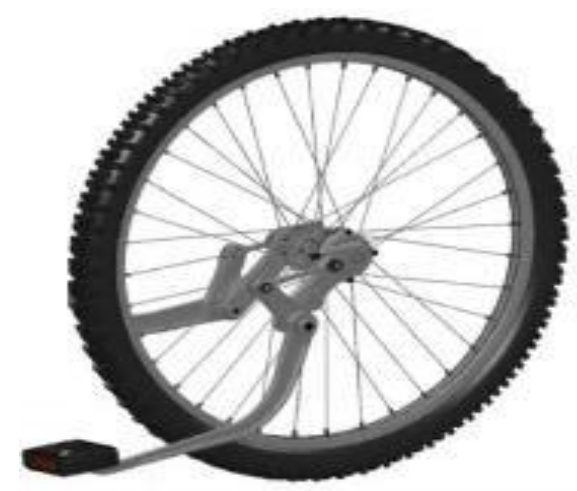

Fig.1 - Wheel System

3) Drive Link: The crank link mechanism is used as the driver linkage. The crank is mounted on the crank shaft that is driven by up and down movement of pedal. The oscillating motion of the crank is then passed onto the output link mounted on the rear. The output link houses a unidirectional clutch such that only the forward motion is given to the rear wheels, where as in the return stroke results in no motion just as it happens when we pedal in reverse direction just as in abi-cycle.

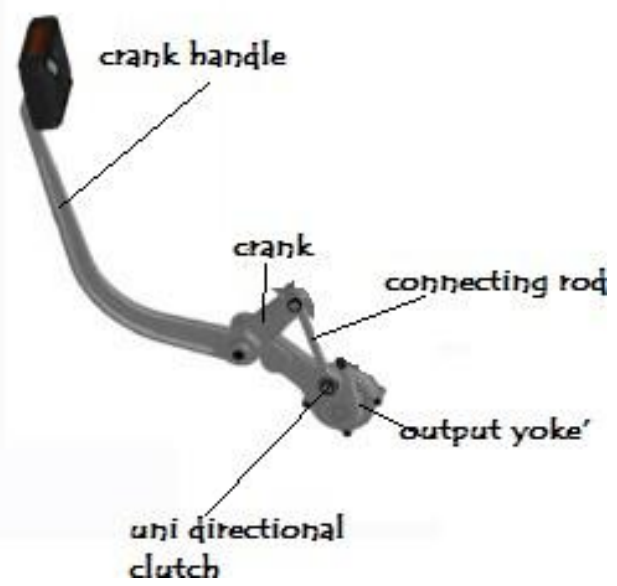

4) Brake mechanism: The brake mechanism is such that when brake is applied the brake shoe on the wheels will stop the motion of the wheels and thus bi-cycle will come to halt.

5) Bush -pin coupling: This coupling is made from bush and pin of for folding mechanism of the bi-cycle. This is a flexible type of coupling.

6) Pedal: A bicycle pedal is the part of a bicycle that the rider pushes with their foot to propel the bicycle. It provides the connection between the cyclist's foot or shoe and the crank allowing the leg to turn the bottom bracket spindle and propel the bicycle's wheels. Pedals usually consist of a spindle that threads into the end of the crank and a body, on which the foot rests or is attached, that is free to rotate on bearings with respect to the spindle. Part attached to crank that cyclist rotate to provide the bicycle power; it consists of three segments as shown in figure

7) Shaft: A shaft is a rotating machine element, usually circular in cross section, which is used to transmit power from one part to another, or from a machine which produces power to a machine which absorbs power. The various members such as pulleys and gears are mounted on it. The material used for ordinary shafts is mild steel. When high strength is required, an alloy steel such as nickel, nickel- chromium or chromium-vanadium steel is used.

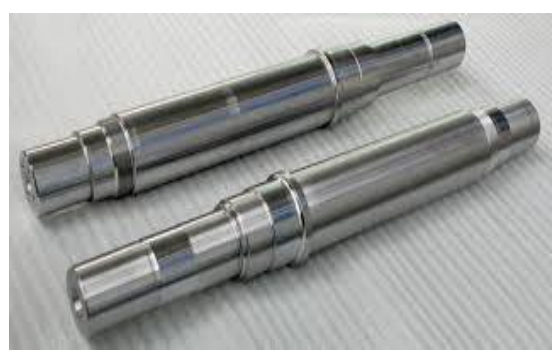

Fig.3 - Shaft

The bicycle pedal is the part of a bicycle that the rider pushes with their foot to propel the bicycle. It provides the connection between the cyclist's foot or shoe and the crank allowing the leg to turn the bottom bracket spindle and propel the bicycle's wheels. Pedals usually consist of a spindle that threads into the end of the crank and a body, on which the foot rests or is attached, that is free to rotate on bearings with respect to the spindle. 


\section{International Journal of Innovations in Engineering and Science, www.ijies.net}

Pedals were initially attached to cranks connecting directly to the driven (usually front) wheel. The safety bicycle, as it is known today, came into being when the pedals were attached to a crank driving a sprocket that transmitted power to the driven wheel by means of a roller chain.

\section{8) Ball bearings-}

A ball bearing is a type of rolling-element bearing that uses balls to maintain the separation between the bearing races. The purpose of a ball bearing is to reduce rotational friction and support radial and axial loads. It achieves this by using at least two races to contain the balls and transmit the loads through the balls.in most applications, one race is stationary and the other is attached to the rotating assembly. As one of the bearing races rotates it causes the balls to rotate as well. Because the balls are rolling they have a much lower coefficient of friction than if two flat surfaces were rotating on each other.Ball bearing tend to have lower load capacity for their size than other kinds of rolling-element bearings due to the smaller contact area between the balls and races. However, they can tolerate some misalignment of the inner and outer races. The bearings are pressed smoothly to fit into the shafts because if hammered the bearing may develop cracks. Bearing is made up of steel material and bearing cap is mild steel.

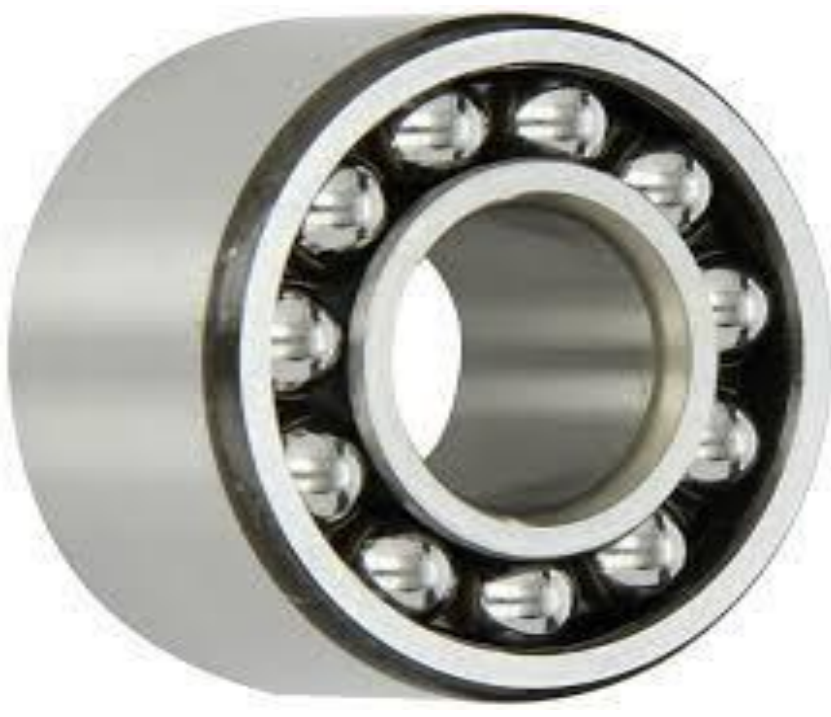

Fig. 4- Ball Bearing

\section{V- WORKING}

The fabrication of the bicycle was done with the help of the CAD drawings. First the hinges were fabricated, followed by t A M6 25mm long nut was welded on the inside of the hinge first. The two half cups were welded on the outer faces of the hinges. Once that was complete, the machined clamp and was assembled with the hinge with the help of quick release levers. The hinge after fabrication is as shown in the figure below.

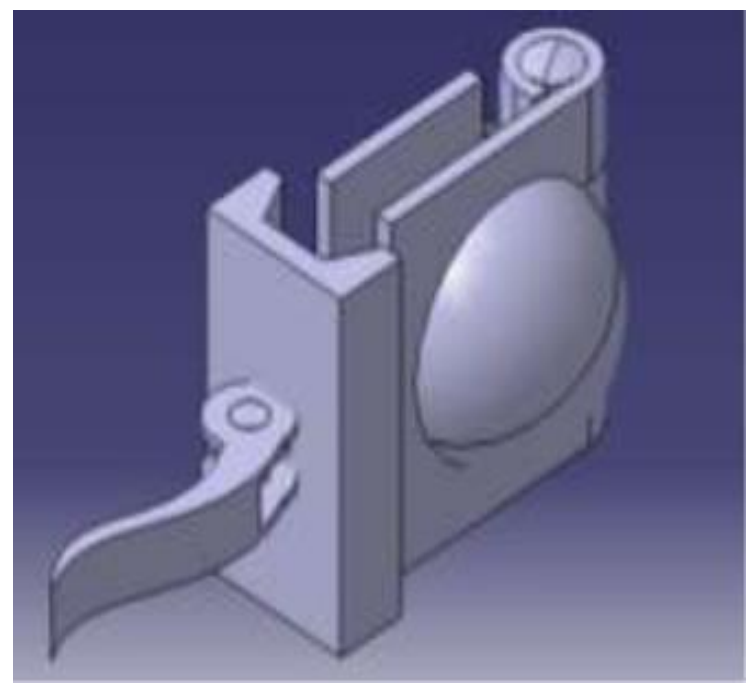

Fig. 5- Hinge Clamp Mechanism

Once the hinge was successfully done, the fabrication of the frame started. First the bottom shell was taken and the seat tube was welded to it. The figure shows how the fabrication was carried out. Once the seat tube was fixed, came the tricky part where the frame tube, the rear part of the frame etc. were to be welded at different angles. With reference to the CAD drawing, the angles were measured and the welding was done carefully and rechecked for errors in angle and straightness of the members. Once the Tubes were welded to the right angle and cut to the required dimension, the hinges were welded to the ends of the tubes, making sure that all the hinge axes were perpendicular to the ground. After the hinges were welded, the hinges were clamped tight and then the rest of the welding began. After the members welded, they were folded and checked for errors. The above figure shows how there are part of the bicycle folds.

Welding of the front end of the frame and the head tube assembly followed. After the welding was done the whole frame was checked for alignment errors and once the errors were rectified the weld was finalized and the process of grinding the joints was carried out. 


\section{International Journal of Innovations in Engineering and Science, www.ijies.net}

Once the whole frame was ready, the wheels were Specimen setup on UTM for Bending test assembled to the frame and the alignment was checked. Then the frame was folded and checked for errors. After the folding errors were checked, the frame was tested for load carrying capacity.

A crank is an arm attached at right angles to a rotating shaft by which reciprocating motion is imparted to or received from the shaft. It is used to convert circular motion into reciprocating motion, or vice versa. The arm may be a bent portion of the shaft, or a separate arm or disk attached to it. Attached to the end of the crank by a pivot is a rod, usually called a connecting rod (conrod). The end of the rod attached to the crank moves in a circular motion, while the other end is usually constrained to move in a linear sliding motion. The term often refers to a human-powered crank which is used to manually turn an axle, as in a bicycle crank set or a brace and bit drill. In this case a person's arm or leg serves as the connecting rod, applying reciprocating force to the crank. There is usually a bar perpendicular to the other end of the arm, often with a freely rotatable handle or pedal attached. The displacement of the end of the connecting rod is approximately proportional to the cosine of the angle of rotation of the crank, when it is measured from top dead center (TDC). So the reciprocating motion created by a steadily rotating crank and connecting rod is approximately simple harmonic motion The mechanical advantage of a crank, the ratio between the force on the connecting rod and the torque on the link varies throughout the crank's cycle.

The fabrication of the bicycle was done with the help of the CAD drawings. First the hinges were fabricated, followed by the frame. with the hinge with the help of

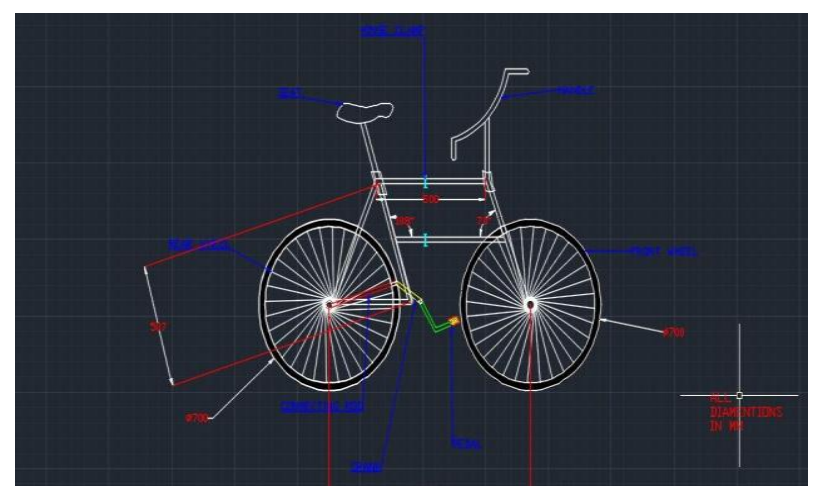

quick release levers.2D Model Of Chainless Bicycle With Folding Mechanism

Fig.6- General layout of Chainless Bicycle with Folding Mechanism

\section{Weight of cycle: Approximately $8 \mathrm{~kg}$}

Mechanism: Slider crank mechanism

Material of cycle :Mild steel

Material of crank mechanism: Mild steel

Folding mechanism: Hinge clamp

Pedal motion :Up and Down

\section{VI- ADVANTAGES}

1) This bicycle can be used by student because it required the less effort.

2) This bicycle can be used for the purpose of exercise.

3) This bicycle can be used by farmer for travelling purpose.

4) This bicycle can be used in the city for the marketing.

5) This bicycle used for public and bicycle rental purpose

\section{VII -CONCLUSION}

This project is very use full for every human being because driving of bicycle is very important for the physical health as well as for saving the fuel and to reduce the pollution This bicycle required the less human effort for pedaling the bicycle and carrying easily because it becomes portable due to folding mechanism. The mechanism becomes robust and more efficient for power transmission as compared to conventional bicycle.

Compared to the foldable bicycles existing in the market, our bicycle is economical and occupies less space. The weight of our bicycle is with par with light weight bicycles available in the market, though the material used for fabrication is mild steel.

The idea of providing a foldable bicycle which is light \& sleek yet rigid \& safe, easy to handle and easy to maintain has been met.

The design of the foldable bicycle was based on the standard data available. The fabrication was done using locally available materials 
Vol. 6, No. 8, 2021, PP. 35-40

International Journal of Innovations in Engineering and Science, www.ijies.net REFERENCES

[1] L.W. Tsai, \& C.C. Lin, The creation of nonfractionated two-degree- of-freedom planetary gear trains, ASME Transactions, Journal of Mechanisms, Transmission, and Transaction in Design, 3, 1989,524-529.

[2] H.S. Yan, \& L.C. Hsieh, Conceptual design for automotive vehicles, ASME Transactions, Journal of Mechanical Design, 116, 1994,565-570.

[3] F. Freudenstein, An application of boolean algebra to the motion of planetary drives, ASME Transactions, Journal of Engineering for Industry, 93, 1971,176-182.

[4] P. P. Lindsey, The design of a folding axontex carbon fibre bicycle frame, MSc Thesis,

[5] University of Hull, (2008), pl.

[6] G. E. Dieter: Engineering Design. 3 ed. (McGrawHill, USA 2000).

[7] M. Farag: Materials and Process Selection for Engineering Design (CRC Press, Taylor \& Francis Groups, USA2008).

[8] A Typical Approach in Conceptual and Embodiment Design of Foldable Bicycle; Arunachalam M, Arun Prakash R, RajeshR.

[9] Welding Hinges, Barrier Components

[10] Bear hardware - WELD-ON HARDWARENEEDS

[11] Bicycle productsNews, an Englishmonthly newspaper on Bicycle trade and industry

[12] Design Data Book forB.D.Sivalkar. 